\title{
Selenium intakes in UK South Asian and Caucasian women: a longitudinal analysis
}

\author{
A. L. Darling, S. Bath, O. Hakim, R. Stoffaneller, M. P. Rayman and S. A. Lanham-New \\ Nutritional Sciences Division, Faculty of Health and Medical Sciences, University of Surrey, GU2 7XH, UK
}

Selenium (Se) is a trace mineral and component of selenoproteins known to be crucial for immune and thyroid function and reproduction $^{(1)}$. Better Se status has also been linked to lower mortality, slower cognitive decline, reduced viral virulence and lower cancer risk ${ }^{(1)}$. Se status in the UK is believed to be low ${ }^{(1)}$. This study used data collected in the D-FINES (Vitamin D, Food Intake, Nutrition and Exposure to Sunlight in Southern England) study to investigate the Se intake of UK women by ethnicity and season. Eighteen- to eightyyear-old Caucasian (mean age $=49$ years, $n$ 248) and South Asian (mean age $=50$ years, $n$ 55) women completed a 4-d diet diary (including one weekend day) in summer, autumn, winter and spring (June 2006-May 2007). Food-portion size photographs were included to aid participant estimation. Data were analysed using Win Diets 2005.

Median Se intakes in Caucasians were 37, 38, 39 and $37 \mu \mathrm{g} / \mathrm{d}$ in summer, autumn, winter and spring, respectively. Median intakes for South Asians in summer, autumn, winter and spring were 35, 30, 36 and 32 $\mu \mathrm{g} / \mathrm{d}$. The figures show that 80-90\% of Caucasians and 83$95 \%$ of South Asians did not meet the RNI $(60 \mu \mathrm{g} / \mathrm{d})$ in any season and, more worryingly, $60 \%$ of Caucasians and $60-70 \%$ of South Asians did not meet the LRNI $(40 \mu \mathrm{g} / \mathrm{d})$. While there was little seasonal change in Caucasian intakes, the South Asians showed a trend for poorer intake in autumn than in the other seasons. There was little difference in the percentage of women not achieving the LRNI or RNI by ethnicity, but there was a trend for Asians to be slightly less likely to achieve them in all seasons.

Data were energy adjusted to allow for differing nutrient requirements. As the data were skewed, log transformation was performed to allow analysis by parametric methods. Independent samples $T$-tests showed statistically significant $(P \leq 0.05)$ differences in energyadjusted Se intakes in autumn $(t=2.515, P=0.012)$ by ethnicity, with South Asian women having a significantly lower intake. However, no difference was found in summer, winter or spring.
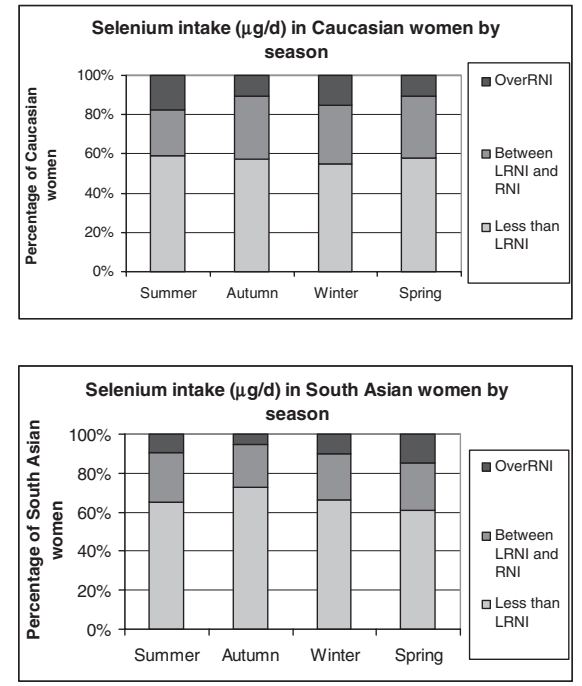

This study highlights the poor Se intakes in UK women and adds novel information about Se intake by season. While overall we found no clear evidence of an ethnic or seasonal difference in Se intake, there was a trend for lower Se intakes in South Asian than in Caucasian women, especially in the autumn. This seasonal trend reflects the findings of the National Diet and Nutrition Survey in elderly people where the lowest Se status was found in autumn ${ }^{(2)}$. Limitations of the study include the acknowledged difficulty in precisely measuring food intake and the high variability in the Se content of foods, which limits the accuracy of the food-composition database used. These results should ideally be confirmed by the measurement of plasma Se. Our finding that $60-70 \%$ of the women did not meet the LRNI for $\mathrm{Se}$ is a matter of public-health concern, given the association between low Se status and a range of chronic health conditions ${ }^{(1)}$.

The D-FINES study was funded by the Food Standards Agency (N05064): all views expressed are the authors' own.

1. Rayman MP (2008) Food-chain selenium and human health: emphasis on intake. Br J Nutr 100, 254-268.

2. Bates C et al. (2002) Selenium status and its correlates in a British National Diet and Nutrition Survey: people aged 65 years and over. Trace Elem Med Biol 16, 1-8. 